\title{
Weaving a web of connections through online citizen science
}

\author{
Cathy Buntting \\ University of Waikato \\ Cathal Doyle, Dayle Anderson and Markus Luczak-Roesch \\ Victoria University of Wellington
}

This article explores how the funding process of New Zealand's Teaching and Learning Research Initiative (TLRI) has catalysed the coming together of an interdisciplinary research team of education researchers, information systems researchers, and teacher practitioners. Through two funded research projects, a large and growing web of connections is being woven, benefiting the research partnership and outcomes. Our collective aim is to investigate the affordances of online citizen science projects to enhance science teaching and learning. Using examples, we trace the development of some key lines of inquiry that have been made possible because of the interdisciplinary foundation of the projects.

Keywords: citizen science, science education, boundary objects

\section{Introduction}

The Teaching and Learning Research Initiative (TLRI) funded by New Zealand's Ministry of Education was established in 2003 and "seeks to enhance the links between educational research and teaching practices to improve outcomes for learners" (tlri.org.nz). As such, partnerships between researchers and practitioners are central to TLRI-funded projects. Specifically, researcher-practitioner partnerships should be integral to the design of the project. There needs to be a focus on the individuals in the team using their collective expertise, and on all team members having the opportunity to learn from each other, rather than on explicitly developing the research skills of the practitioner members of the project team (TLRI, 2020, p. 4).

This article is based on the connections that have been made between researchers, teachers and others through two different TLRI-funded projects - Citizen scientists in the classroom: Investigating the role of online citizen science in primary school science education (2018), and On2Science: Multiple affordances for learning through participation in online citizen science (2020-2023). Our intention is to demonstrate the ways in which the partnership ethos of the TLRI has shaped the direction of our travel.

\section{Finding common ground}

In 2017, computer scientist Markus Luczak-Roesch and Information Systems researcher Cathal Doyle, both from Victoria University of Wellington's School of Information Management, wondered about ways to connect with education research colleagues. An early conversation with Dayle Anderson and Azra Moeed, both based in the University's 
School of Education, identified some possible areas of overlapping interest. Further explorations identified online citizen science (OCS) projects as a jumping off point for collaboration.

In citizen science projects, members of the public contribute to scientific projects by assisting with one or more of the following: data collection, data processing, data analysis and interpretation, and disseminating results. In online citizen science, the tasks to be completed are aided, or completely mediated, through the Internet. In general, the aim of citizen science and OCS projects is to broaden public participation in science - with benefits to both the scientific question being investigated, and the participants (Eitzel et al., 2017). An increasing number of schools in New Zealand and globally are using citizen science as a means of engaging students in authentic science investigations. For example, the New Zealand Government's investment in the Participatory Science Platform pilot projects in Otago, Taranaki and South Auckland has resulted in a wide range of initiatives between schools, science organisations and other communities (see www.curiousminds.nz/funding/participatory-science-platform/). OCS projects broaden the scope for engagement, making citizen science more accessible to a larger number of volunteers, often without regional restrictions.

While there is a growing literature reporting the impacts of engaging in local, or even globally-connected citizen science projects, fewer published studies report on the impacts of student participation in citizen science projects that have a significant online component. Where they do exist, the reports tend to focus either on student engagement, or on teacher practice in order to demonstrate the scaffolding that is needed for learning opportunities to be maximised (Anderson et al., 2020). Being able to contribute to authentic science projects - something bigger than themselves - seems to be a key aspect that drives students' engagement. For example, Brunvard and Bouwman (2018) report that by contributing to a large, international dataset, fifth graders in Michigan became "respectful stewards of data" (p. 54).

Markus and Dayle began wondering about the wider potential for learning when primary school students contribute to OCS projects as part of their school science programmes. A 2018 pilot project was successfully funded by the TLRI. This project brought together researchers and advisors from Victoria University of Wellington's School of Information Management and School of Education, Waikato University's Division of Education, and four teachers from four different primary schools in the wider Wellington region (see Figure 1).

Consistent with the TLRI kaupapa (purpose), the project was co-constructed by the wider research team, including the participating teachers. The aim was to explore the impacts of using an OCS project in primary school science programmes. The teachers selected the OCS that they would use, the focus of their unit, and the science capabilities (see Hipkins \& Bull, 2015) that they were supporting their students to develop. In several cases, they reached out to the scientists involved in the OCS projects they were using, or who had relevant expertise - widening the range of expertise contributing to the project. 


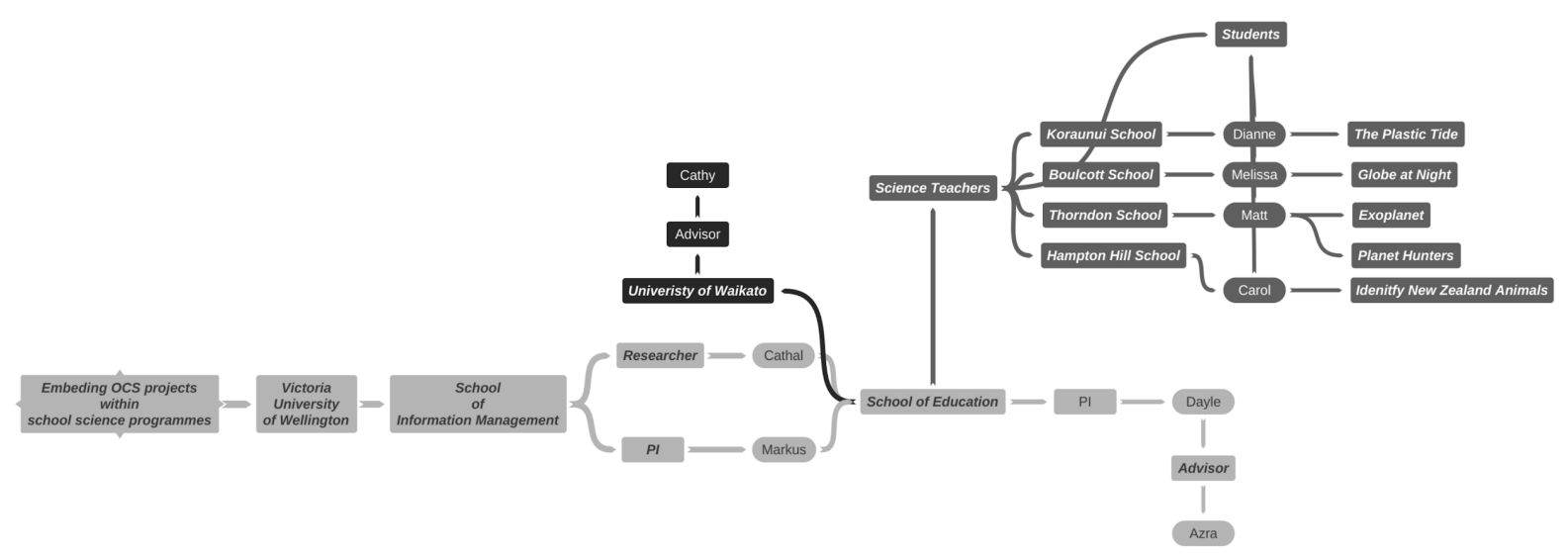

Figure 1. Starting to weave a web: How the 2018 research project brought together interdisciplinary experts from across academia and the teaching profession

Research data included recordings of team meetings, teacher planning documents, classroom observation notes, student work samples, focus group interviews with students, and teacher questionnaires and interviews. Reflecting the different disciplinary interests and expertise across the team, insights were gained in relation to pedagogical practices that supported students' science learning, criteria for selecting OCS projects for classroom use, and aspects of OCS platform design that support student engagement and learning (see Anderson et al., 2020; Doyle et al., 2020). In addition, the team considered the apparent impacts of different human-computer interactions $(\mathrm{HCl})$ on peer communication amongst students (see Luczak-Roesch et al., 2019). The team collaborated with the Science Learning Hub (sciencelearn.org.nz) to share the findings more broadly. The Hub, funded by the Ministry of Business, Innovation and Employment to connect New Zealand's science and education sectors, developed a new 'citizen science' section as part of this collaboration. Digital resources that have been developed include case studies of the four classroom interventions, recorded webinars with the participating teachers, and a growing and searchable collection of citizen science project profiles that provide a bouncing-off point for teachers wanting to find projects that could connect with their programme planning.

\section{Extending the web}

The 2018 pilot raised further research questions that we were keen to continue exploring. In addition, the new digital technology progress outcomes had been released, as had a series of indicators for each of the science capabilities at Levels 2 and 4 (Ministry of Education, 2019). A 2019 project proposal, successfully awarded funding for 2020-2023, was designed to extend the pilot by: (1) mapping progressions in students' science capabilities across NZC Levels 2-4, (2) identifying affordances of OCS engagement for developing students' digital technologies progress outcomes, and (3) investigating the impacts of teacher practices in relation to human-computer interactions. In other words, the proposed project would build on the nascent work of the Ministry of Education to identify progress indicators for the science capabilities, and align with the introduction of the digital technologies curriculum. In addition, questions around individual versus group engagement with digital devices raised in the pilot would be pursued. A three-year project was proposed to enable the three interwoven strands of science capabilities, digital 
technology learning, and $\mathrm{HCl}$ to be explored in-depth, recognising the enabling trajectory for teacher professional learning across the three areas of investigation.

The new project's goals were once again co-constructed to reflect the interests and expertise across the team, as well as changes in the education landscape. In addition, our team grew (see Figure 2). Three new teachers contribute intermediate and junior secondary expertise and extend the age range of students who would engage in the wider project. In addition, Dr Rose Hipkins from the New Zealand Council for Educational Research contributes expertise in students' science capability development and Stephen Ross from Te Whai Toi Tangata, Institute of Professional Learning, University of Waikato contributes expertise in relation to the digital technology curriculum.

During the 2020 year, teachers once again chose the OCS projects that they would engage with, with some also reaching out to the participating scientists. For example, teacher Richie Miller and his students at Newlands College were able to share a 'Zoom' session with the United Kingdom-based lead scientist of Planet 4 (www.zooniverse.org/projects/mschwamb/planet-four). In this OCS project, participants analyse images taken of the surface of Mars, identifying features that provide weather indicators like wind direction. The project anchored the design of the teaching and learning sequence, which required students to collect and use evidence to decide on the viability of life on Mars (see Buntting \& Miller, 2020). Teacher Matt Boucher and project lead Cathal Doyle used the Covid-19 enforced lock-down to design a new OCS project How to fight microscopic beasts: the grand experiment - embedded in an online course that Matt designed (Education Gazette editors, 2020). Across the project, a new research question also emerged: How were science teachers continuing to support students' science learning through school-led learning at home?

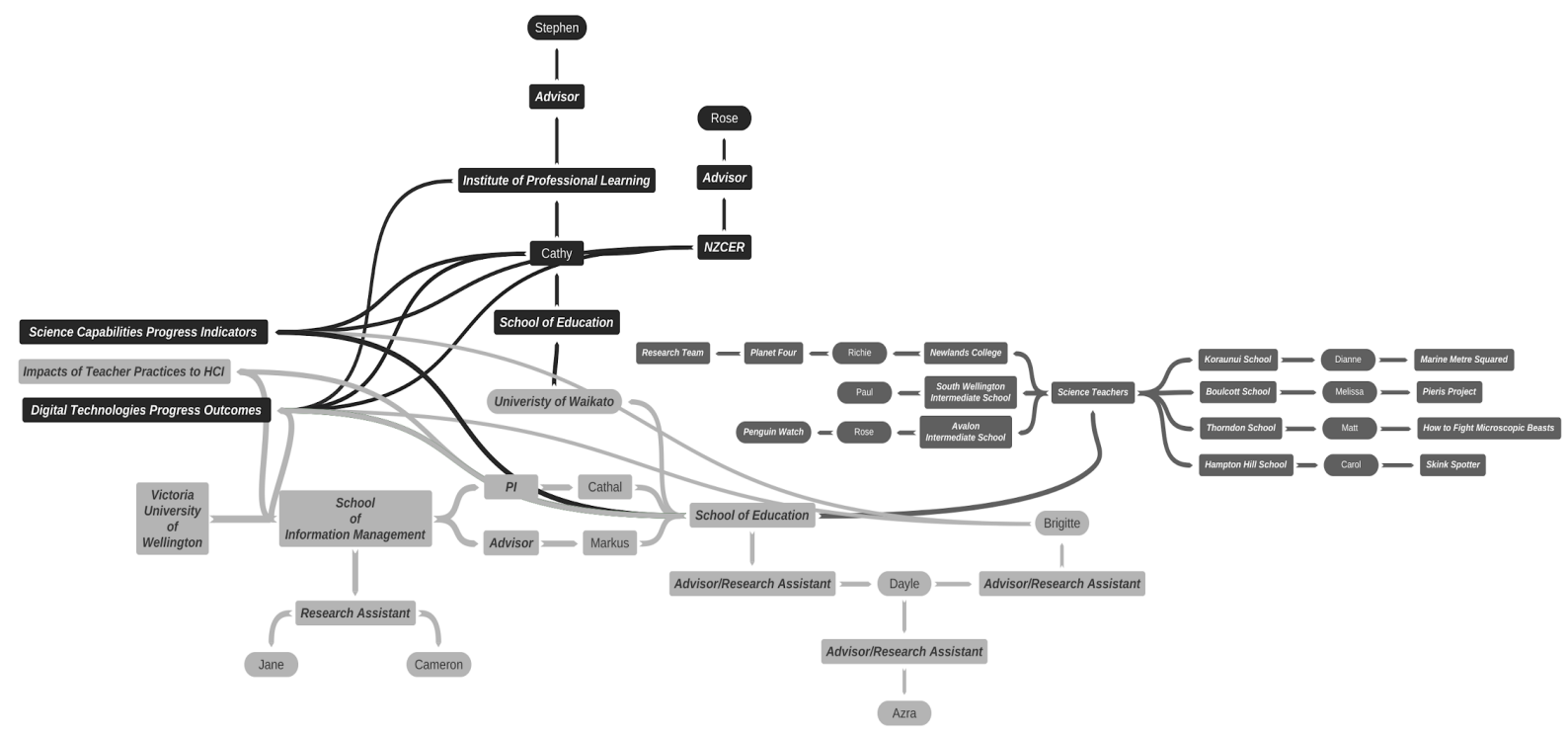

Figure 2. Extending the web: Bringing in additional expertise to explore the three overlapping areas of science capability development, digital technology learning outcomes, and human-computer interactions 


\section{Working across boundaries}

The concept of boundaries has been used by an increasing number of scholars to explore both the ways in which individuals navigate multiple sociocultural contexts, and the ways in which individuals from different sociocultural contexts interact dialogically with each other. The underpinning premise is that boundaries carry learning potential (Akkerman \& Bakker, 2011). In the two TLRI projects described above, one of which will continue for another two years, we have grown increasingly interested in tracking the ways in which the interdisciplinarity of the team has shaped the research directions, including the questions that we ask, the methods we use, and the ways in which we analyse the data and present our findings. We are mindful, for example, of the need to be able to engage credibly with audiences that span teacher professional communities, science education research communities, digital technology education research communities, and OCS platform designers.

One idea we are currently pursuing is the notion of 'boundary objects' as artifacts that support boundary crossing by fulfilling a bridging function (Akkerman \& Bakker, 2011). We propose, for example, that our research questions, data collection protocols, project data (e.g., teacher unit plans, classroom observation notes, student work samples), coding protocols, and even our draft case studies represent boundary objects in the sense that they facilitate dialogue between team members and - ideally - enable assumptions and biases to be identified and articulated. We know, for example, that there is benefit in having both an education researcher and an information systems researcher observe the same classroom interactions as the two invariably notice different aspects because of their areas of interest and expertise. These notes then become a tangible 'object' that can be used to prompt teacher reflections and wider dialogue in assigning meaning to particular episodes.

\section{Concluding thoughts}

This story began with four researchers, the computer scientists who were looking for interdisciplinary collaboration opportunities, and the education researchers who were open to such opportunities. As a result, an initial conversation that may have stopped with a collegial 'meet and greet' has instead led to the development of a rich and interconnected research ecosystem. As a wider project team, we feel grateful to be involved in a collaboration that has shared purpose and meaning, and through which we learn deeply from each other. There is no doubt that much of the success of the collaboration to date is based on a strong sense of mutual respect for what each person contributes, and a genuine commitment to a shared kaupapa. The 'lenses' we each bring to the research design, data gathering and data analysis differ, and it is because of these differences and a determination to examine them that we hope new insights will continue to emerge. We therefore acknowledge the enthusiastic commitment of Carol Briesman (Hampton Hill School), Matt Boucher (Thorndon School), Rose Campbell (Avalon Intermediate), Dianne Christenson (Koraunui School), Melissa Coton (Boulcott School), Richie Miller (Newlands College), Yevgeniya 'Jane' Li (Victoria University of Wellington), Brigitte Glasson, Cameron Pierson, and Azra Mooed. We acknowledge, too, the kaupapa of the Teaching and Learning Research Initiative, the emphasis that the TLRI places on partnership, and the funding that has supported this particular collaboration. 


\section{References}

Akkerman, S. F., \& Bakker, A. (2011). Boundary crossing and boundary objects. Review of Educational Research, 81. https://doi.org/10.3102/0034654311404435

Anderson, D., Buntting, C., \& Coton, M. with Luczak-Roesch, M., Doyle, C., Pierson, C., Li, Y., Glasson, B., Brieseman, C., Boucher, M., \& Christenson, D. (2020). Using online citizen science to develop students' science capabilities. Curriculum Matters, 16, 38-59.

Brunvand, S., \& Bouwman, J. (2018). A global perspective. Fifth graders practice data collection as they examine soil. Science and Children, 50-55.

Doyle, C., Rodreck, D., Li, Y., Luczak-Roesch, M., Anderson, D., \& Pierson, C., M. (2019). Using the web for science in the classroom: Online citizen science participation in teaching and learning. WebSci '19: Proceedings of the $10^{\text {th }}$ ACM conference on web science. https://dl.acm.org/doi/10.1145/3292522.3326022

Doyle, C., Luczak-Roesch, M., Li, Y., Anderson, D., Glasson, B., Khanal, P., Boucher, M., Brieseman, C., Christenson, D., \& Coton, M. (2020). A working definition of online citizen science. Author. https://doi.org/10.22541/au.152565467.70918550

Education Gazette editors. (2020). Mouldy bread and microscopic beasts. Education Gazette, 99(12). https://gazette.education.govt.nz/articles/mouldy-bread-andmicroscopic-beasts/

Eitzel, M. V., Cappadonna, J. L., Santos-Lang, C., Duerr, R. E., Virapongse, A., West, S. E., Kyba, C. C. M., Bowser, A., Cooper, C. B., Sforzi, A., Metcalfe, A. N., Harris, E. S., Thiel, M., Halday, M., Ponciano, L., Roche, J., Ceccaroni, L., Shilling, L., Dorler, D., ... Jiang, Q. (2017). Citizen science terminology matters: Exploring key terms. Citizen Science: Theory and Practice, 2(1), 1-20. https://doi.org/10.5334/cstp.96

Hipkins, R., \& Bull, A. (2015). Science capabilities for a functional understanding of the nature of science. Curriculum Matters, 11, 117-133.

Miller, R., \& Buntting, C., \& (2020, October). Travelling to Mars? Oral presentation at ULearn. Virtual conference. https://www.youtube.com/watch?v=Bpl Axag59k

TLRI. (2020). Expression of interest. http://www.tlri.org.nz/sites/default/files/pages/TLRI\%20Expression\%20of\%20Interest\% 202020\%20-\%20GUIDANCE\%20\%281\%29.pdf

Cathy Buntting is Director of the Wilf Malcolm Institute of Educational Research, University of Waikato as well as Director of the award-winning Science Learning Hub and Principal Investigator for On2Science: Multiple affordances for learning through participation in online citizen science. Her research interests straddle science, technology and STEM education across the school years, with a strong focus on innovative approaches to education in these disciplines. She is passionate about the teaching- 
research nexus, and much of her research has led to the development of teacher-facing educational resources.

Email: cathy.buntting@waikato.ac.nz

ORCiD: https://orcid.org/0000-0002-1507-9415

Dr Cathal Doyle is a senior lecturer at the School of Information Management, Victoria University of Wellington. He is a Principal Investigator for the TLRI project On2Science: Multiple affordances for learning through participation in online citizen science where the focus is on understanding how online citizen science can be used in the classroom. His research platform runs across three strands: design science research (DSR); technology and learning; and open science. His contributions come in both practical artefacts for professionals to use to solve problems, as well as theoretical in terms of how these stands can be developed further.

Email: cathal.doyle@vuw.ac.nz

ORCiD: https://orcid.org/0000-0001-5633-3654

Dr Dayle Anderson is a senior lecturer in initial teacher education in the Faculty of Education at Victoria University of Wellington. She is an experienced researcher in the field of primary science education with a number of international publications and national and international collaborations. She was a Principal Investigator for the Citizen Scientists in the Classroom project. Her research is largely classroom based and focuses on supporting and developing primary teachers' practice for science. Dayle is a cofacilitator of science education professional development for the Royal Society $\mathrm{Te}$ Apārangi's Science Teaching Leadership Programme.

Email: dayle.anderson@vuw.ac.nz

ORCiD: https://orcid.org/0000-0002-6995-8116

Associate Professor Markus Luczak-Roesch leads the Complexity and Connection Science Lab at Victoria University of Wellington, where he is situated within the School of Information Management. The lab's work is focused on theories and methods to understand the structures and dynamics of complex systems, and the development of Software tools that securely and meaningfully augment human intelligence. Markus Luczak-Roesch is also an Associate Investigator at Te Pūnaha Matatini - New Zealand's Centre for Research Excellence on Complex Systems and Networks. Before joining Victoria University of Wellington in 2016, he held a Senior Research Fellow position at the University of Southampton, working on the prestigious project SOCIAM - The Theory and Practice of Social Machines (https://sociam.org/), which devised novel methods to understand the emergent socio-technical problem solving capabilities that arise on the World Wide Web.

Email: markus.luczak-roesch@vuw.ac.nz

ORCiD: https://orcid.org/0000-0003-4610-7244 